\title{
When are optimal rates of presentation optimal (for learning)?
}

\author{
WILLIAM L. CULL, CATHERINE A. D'ANNA, ERNIE J. HILL, \\ and EUGENE B. ZECHMEISTER \\ Loyola University, Chicago, Illinois \\ and \\ JAMES W. HALL \\ Northwestern University, Evanston, Illinois
}

\begin{abstract}
It has been shown previously that with total time held constant, several relatively brief presentations of a simple verbal item (e.g., four presentations at a 2-sec rate) produce better associative learning than does one lengthy presentation (e.g., one presentation at an 8-sec rate). In two experiments, we examined the generality of this effect. In Experiment 1, presentation rate was examined in relation to the ability of the learner (good and poor associative learners) and the difficulty level of to-be-learned items (hard and easy items). In Experiment 2, the effect of presentation rate was examined as a function of the retention interval (immediate or delayed). The results indicate that the effect is robust, and apparently independent of ability of learner, type of item, and time of testing. Implications for planning optimal learning strategies, especially those that might be employed for acquiring new vocabulary, are discussed.
\end{abstract}

Several studies have recently refocused attention on the methods by which associative learning-for example, simple vocabulary learning - is affected by rate and distribution of presentation (e.g., Dempster, 1987; Hall, Owens, $\&$ Wilson, 1987). The issue has both theoretical and practical implications (see also Dempster, 1988; Landauer \& Bjork, 1978). For example, Hall and Fuson (1986) have pointed out that relatively slow rates of presentation are often typical of control groups used to assess the effect of mnemonic training. Yet several experiments (see, e.g., Hall et al., 1987) have shown that several brief presentations (e.g., four repetitions at a 2 -sec rate) produce better learning than does one presentation at a longer rate (e.g., $8 \mathrm{sec}$ ). Thus, the use of nonoptimal rates of presentation may have led to an overestimation of the effects of certain mnemonic techniques.

The issue of concern in the present experiment is the extent to which optimal presentation schedules depend on (1) learner characteristics and (2) item characteristics. One might imagine, for example, that slow learners require longer presentation durations than fast learners do. Similarly, one might expect that the optimal presentation duration increases with item difficulty. These possibilities were examined in Experiment 1, wherein fast and slow learners were presented hard and easy verbal items

\footnotetext{
We wish to acknowledge support provided by a small grant from the Loyola University Research Services department. Results of these experiments were reported at the meeting of the Midwestern Psychological Association in Chicago, May 1990. Requests for reprints should be sent to Eugene B. Zechmeister, Psychology Department, Loyola University of Chicago, 6525 N. Sheridan Rd., Chicago, IL 60626.
}

either four times at a 2-sec rate or once at an 8-sec rate, as in Experiment 1 of Hall et al. (1987).

\section{EXPERIMENT 1}

\section{Method}

Subjects. The subjects were 68 undergraduates who participated as part of a requirement for an introductory level psychology course. The subjects were randomly assigned to two between-subject conditions and were tested in pairs in a small laboratory room equipped with two Apple computers and monitors

Material. Two lists of five-letter word pairs were constructed from a pool of 200 pairs previously shown by Underwood (1982) to differ reliably in learning difficulty. The first list comprised 20 word pairs of relatively average difficulty. For the second list, half the items were chosen from Underwood's 100 easiest word pairs and half were chosen from his 100 hardest word pairs. Each pair in the second list was selected so that a relatively uncommon word was the left-hand member and a relatively common word was the right-hand member. This particular type of item was selected because it resembles the kind of items that are involved when one learns the meanings of uncommon English words. Examples of easy pairs are villi-under, durst-brown; examples of hard items are loess-trial, and quash-fiber. There were 36 total pairs in the second list-18 easy word pairs and 18 hard word pairs.

Procedure. The first list provided both a warm-up task and a basis for classifying subjects as fast or slow associative learners. The 20 word pairs were presented at a study rate of $4.5 \mathrm{sec}$ and at a test rate of $8 \mathrm{sec}$. For the test items, only the left-hand member of each word pair was presented, and the subject attempted to recall the right-hand member. Responses were recorded by subjects on answer sheets. There were two study-test trials on List 1.

Following List 1 learning, the subjects learned the 36 List 2 word pairs under one of two different presentation conditions. In the first condition, the 36 pairs were presented four times at a 2 -sec study rate. That is, four study trials with no intertrial interval were presented prior to a test trial. In the second condition, the subjects saw each of the pairs one time for $8 \mathrm{sec}$ before the test trial. In both conditions, therefore, each item was presented for $8 \mathrm{sec}$ prior to each of two test trials. Items 
Table 1

Mean Performance (with Standard Deviations) in Conditions of Experiments 1 and 2

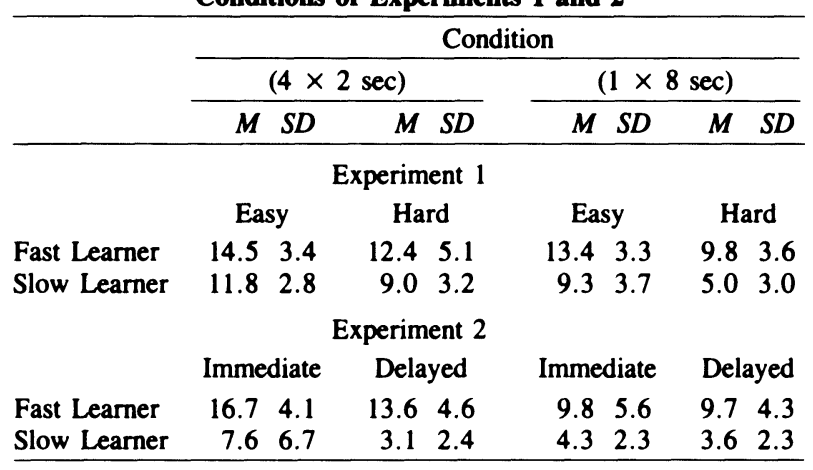

were presented in a new random order on each study trial; the order of items on the test trials was the same for both test trials. Test rate was $8 \mathrm{sec}$.

\section{Results and Discussion}

Associative learning ability was defined on the basis of List 1 learning. Within each rate condition, the subjects were ordered in four blocks defined by the number of words recalled on the second test trial of List 1. Equal numbers of subjects were then randomly selected from corresponding blocks in each rate condition. This post hoc blocking procedure resulted in 22 fast and 22 slow subjects in each between-subjects condition. Mean correct responses on List 1 for subjects classified as fast (Blocks 1 and 2) and those classified as slow (Blocks 3 and 4) were 16.6 and 8.0 , respectively.

Mean correct responses on the second test trial of List 2 of fast and slow learners for the two levels of item difficulty and for both presentation rates are shown in the top half of Table 1 . A $2 \times 2 \times 2$ mixed analysis of variance was used to analyze number correct responses on the second test trial of List 2 . (All inferences are made with alpha set at .05.) Easy word pairs were more easily recalled than were hard word pairs $[F(1,40)=43.85$, $\left.M S_{\mathrm{e}}=5.01\right]$; fast learners recalled more word pairs than did slow learners $\left[F(1,40)=14.75, M S_{\mathrm{e}}=20.98\right]$; and presenting items for study four times at a 2 -sec rate produced greater recall than did presenting items one time for $8 \mathrm{sec}\left[F(1,40)=6.92, M S_{\mathrm{e}}=20.98\right]$. No interactions between the variables were significant. Thus, the results suggest that the effect of distributed, rapid presentation is quite robust and generally effective across different rates of presentation and for different types of learners.

\section{EXPERIMENT 2}

Although the results of Experiment 1 extend the generality of the rate effect, it still may be suggested that the effect is an artifact of the method of testing. When study time is distributed at a rapid rate, the length of time between the last presentation of an item and its appearance on the test trial is on the average less than it is when study involves a single, lengthy presentation of each item. For example, if there are 24 items in the list and each item is presented four times for $2 \mathrm{sec}$, the interval between when an item is last studied and the beginning of the test trial will be on the average $24 \mathrm{sec}$. For the same number of items presented at an 8-sec rate, this interval will average $96 \mathrm{sec}$. In Experiment 2, retention was tested both immediately following a study trial (as in Experiment 1) or after an interpolated delay of $8 \mathrm{~min}$. Although retention interval is confounded whenever there are variable study rates, any artifact associated with the difference in retention interval would be expected to have less of an impact as the interval between study and test increases.

\section{Method}

Subjects. Eighty students participated. Once again they were undergraduates participating as part of a requirement for an introductory level psychology course; however, no subject was tested who previously had participated in Experiment 1. The subjects were tested in pairs in the same room.

Material. The first list used in Experiment 1 was employed in Experiment 2 in the same role. The second list of Experiment 1 was shortened to include only 24 items -18 easy and 6 hard. This was done in an attempt to avoid a basement effect following the single study-test trial of Experiment 2. A math test was used as a filler task for the subjects in the delay conditions.

Procedure. As in Experiment 1, all subjects first learned a list of 20 word pairs of average difficulty for two study-test trials. The subjects then were presented the second 24-pair list at either a rapid (distributed) rate $(4 \times 2 \mathrm{sec})$ or a relatively slow rate $(1 \times 8 \mathrm{sec})$ of study. Half of the subjects were tested immediately after a single study series, and the other half were tested following $\mathbf{8}$ min of the math filler task.

\section{Results and Discussion}

As in Experiment 1, fast and slow associative learners were defined on the basis of List 1 learning. The number of learners from fast and slow blocks was balanced by randomly dropping subjects so that there were equal numbers of subjects in the four rate-delay conditions. The mean numbers of correct responses made by fast and slow learners on the single test trial of List 2 in each of these conditions are shown in the bottom half of Table 1. More words were recalled on immediate tests than on delayed tests $\left[F(1,64)=4.04, M S_{\mathrm{e}}=18.82\right]$. Fast learners recalled more words than did slow learners $[F(1,64)=$ 57.8]; and $4 \times 2 \mathrm{sec}$ study elicited greater recall than did $1 \times 8$ sec study $[F(1,64)=10.98]$. The only significant interaction was that of rate $\times$ learner $[F(1,64)=4.04]$. Inspection of the means in Table 1 shows that fast learners appeared to benefit more from the $4 \times 2 \mathrm{sec}$ rate than did slow learners. The interaction is inconsistent with the results of Experiment 1, and we believe that it likely results from a basement effect in the performance of the slow learners studying in the $1 \times 8 \mathrm{sec}$ condition (see Table 1). More importantly, it appears that the differential interval between study and testing cannot account completely for the effect of rapid, distributed study. Learning was greater in this condition even when tested after a delay of $8 \mathrm{~min}$. Close inspection of the means in Table 1 , however, shows that performance did not decrease between immediate and delayed testing as much following $1 \times 8$ sec study as it did following $4 \times 2$ sec study. 
Again, this may be due in part to an apparent basement effect in the delayed testing following $1 \times 8 \mathrm{sec}$ study.

The results of the two experiments indicate that optimal conditions for simple associative learning involve multiple, relatively brief presentations of items. Although the precise rate-frequency combinations that are optimal have yet to be worked out, for these materials there appears to be no obvious interaction between the rate of presentation and either ability of learner or difficulty level of the item. Moreover, the effect does not seem to be explained by the inherent confounding of retention intervals for this comparison. Our view of the processes underlying this effect is similar to the "attention" explanation frequently given for an effect of distributed versus massed practice (see, e.g., Zechmeister \& Nyberg, 1982). Specifically, we suggest that a subject's attention will wane quickly during a single, lengthy study interval and, therefore, that functional study time will be substantially greater following several dispersed and relatively rapid study opportunities than it will following a single ("massed"), lengthy study opportunity.

Because the items used in the present experiments were selected to resemble the kind of items encountered when one is acquiring new vocabulary (unfamiliar stimulus and familiar response), the results would appear to have par- ticular implications for establishing optimal conditions for vocabulary learning.

\section{REFERENCES}

DEMPSTER, F. N. (1987). Effects of variable encoding and spaced presentations on vocabulary learning. Journal of Educational Psychology, 79, 162-170.

DEMPSTER, F. N. (1988). The spacing effect: A case study in the failure to apply results of psychological research. American Psychologist, 43, 627-634.

Hall, J. W., \& Fuson, K. C. (1986). Presentation rates in experiments on mnemonics: A methodological note. Journal of Educational Psychology, 78, 233-234.

Hall, J. W., OWENS, W. L., \& Wilson, K. P. (1987). Presentation rates and keywords in vocabulary learning. Bulletin of the Psychonomic Society, 25, 179-181.

LANDAUER, T. K., \& BJORK, R. A. (1978). Optimum rehearsal patterns and name learning. In M. M. Gruneberg, P. E. Morris, \& R. N. Skyes (Eds.), Practical aspects of memory (pp. 625-632). New York: Academic Press.

UNDERWOOD, B. J. (1982). Paired associate learning: Data on pair difficulty and variables that influence difficulty. Memory \& Cognition, 10, 610-617.

ZeChMeISTER, E. B., \& NyBeRG, S. E. (1982). Human memory: Research and theory. Pacific Grove, CA: Brooks/Cole.

(Manuscript received July 19, 1990.) 